\title{
EXPERIMENTAL ONLINE CASE STUDY FOR A BREAKTHROUGH IN STUDENT ENGAGEMENT: FOCUS GROUP RESULTS
}

\author{
James Theroux \\ Isenberg School of Management \\ University of Massachusetts \\ Amherst, MA 01003 \\ Email: theroux@som.umass.edu \\ Telephone: 413-545-5677 \\ Cari Carpenter \\ Isenberg School of Management \\ University of Massachusetts \\ Amherst, MA 01003 \\ Email: ccarpent@som.umass.edu \\ Telephone: 413-545-4037 \\ Clare Kilbane \\ School of Education \\ University of Massachusetts \\ Amherst, MA 01003 \\ Email: kilbane@educ.umass.edu \\ Telephone: 413-577-2898
}

\begin{abstract}
A new type of case study, called the real-time case (RTC), was produced in the fall of 2001 and distributed via the Internet to business classes at four universities in the US and Canada. The real-time case presented the story of one company's growth and development throughout a 14-week semester. A case writer stationed full-time at the subject company published case installments weekly on the Web, allowing students to view the company-building process as it happened. The 14-week coverage of RTC enabled students to study the subject company in unprecedented depth and detail. RTC's real-time interactivity allowed students to share their analyses and best thinking with the company leadership during the company's decision-making process.
\end{abstract}

A major objective in producing the case was to heighten student engagement with the case material. To evaluate whether this objective was achieved, a survey and a focus group discussion were conducted with one of the participating MBA classes. Results from the survey and the focus group showed a high degree of engagement, plus many other benefits from the new type of case study. 


\section{KEY WORDS}

Real-time, Live case study

\section{INTRODUCTION}

During fall 2001 a consortium of four business schools participated in a new type of business case study called the Real-Time Case (RTC). Here is the course description that students encountered at the four universities:

As you read this, the managers of a new high-tech company, Optasite Inc., are striving to achieve the entrepreneurial dream. On a password-protected website you will follow that company, and see their progress week by week. But you will do more than just watch. You will be actively engaged with the company, analyzing its problems, and making input. You will be participating in the first in-depth, realtime case study.

Unlike traditional case studies, this real-time case will dig deeply into one company during the entire semester. At this moment, a case writer is stationed full-time at the case company. Each week the writer will provide us with the information we need to analyze a particular problem or question faced by the company. But our goal is not analysis for its own sake. Instead, we want to go beyond critiquing, and make valuable recommendations to the company. The company is counting on us to perform, and we want to deliver.

Because the real-time case covered one company for an entire semester, students became immersed in substantially more detail and complexity than is possible in a traditional case study. Because the case company was studied in real-time, there was a sense of urgency and immediacy that transformed the classroom dialog from pure analysis to personal involvement. Because the case data unfolded week by week, and was received by the students and the professor at the same time, the student-professor relationship became a problem-solving partnership.

The traditional case method has changed little in over a hundred years. The Internet presents an opportunity to revamp the case method. In our view, the case method is the best tool that business educators have at their disposal. But there are shortcomings. The traditional case is produced over a 1218 month period. A case hot off the press is rarely less than a year and a half old. Meanwhile companies and technologies change so fast that a new case is often outdated when it arrives in students' hands. Furthermore, because the Internet provides students easy access to business news and information, the "cliffhanger" aspect that is essential to the drama of many cases is lost.

An additional limitation of the case method is the brief nature of individual cases. In ten or so pages it is not possible to provide students with the detail and background necessary for a well-informed decision analysis. The Internet, harnessed for the production of a full-semester case in real time, can address this problem.

Another motivation for efforts to improve the case method is that students' expectations are changing. More students have work experience and expect a practical, realistic curriculum. Our media-saturated world allows them to be connected with the world in every aspect of their lives; why not business education? This question led us to wonder, could studying cases in real-time lead to more engaged students and better learning outcomes? 


\section{DESCRIPTION OF THE ONLINE CASE STUDY}

\section{A. Participating Students}

The real-time case method was used for both MBA students and undergrad business majors during the fall 2001 semester. A total of 112 students in classes at four universities experienced the real-time case. This paper reports the results from a subset of the 112 students: a focus group discussion with an MBA level course at the University of Massachusetts.

\section{B. Major Educational Objectives}

The real-time case method presumes the value of the traditional case method and shares its objectives in terms of teaching content and teaching analytical skills. But the real-time case goes a bit farther and aims to do the following: 1) increase student engagement with the material, 2) increase student motivation to study the material, 3) make the material more memorable, and 4) provide students with a greater appreciation of the complexity and interdisciplinary nature of business decisions.

\section{Innovative and Unique Features}

To the best of our knowledge, and after a thorough review of the literature, no one has ever attempted to do a full-semester case study on a single company that is 1) done in real-time, and 2) written with the same level of quality and in the same format as conventional cases. Prior to the Internet there would be no practical way to do such a project. Nor would the project be possible without placing a case writer inside the case company full-time, almost like an anthropologist. And because we followed the company's activities as they were happening, we were able to utilize every imaginable technology to connect students to the case company, including video conferences, phone conferences, online chat, threaded discussions, and so on.

\section{Content}

The real-time case focused on a wide array of classic business topics such as marketing strategy, venture capital, human resource management, product definition, and competitive analysis. The topics were driven by the actual issues facing our case company, which was (and is) a high-tech startup.

\section{E. Organization}

The basic organization of the course was to deliver to students a weekly case study on a new problem or issue facing the case company. New case installments were posted on the course website on Saturdays at 6:00pm. During the semester, fourteen such case installments were posted, all dealing with a different decision that the company needed to make. And each week students would analyze the problem at home on their own. Several days later they would come to class for a standard type of case discussion focused on finding a solution to the company's problem. Class recommendations were then forwarded to the case company via the on-site case writer. Students could also post questions about the company, which the case writer would answer, providing a level of engagement and interactivity not possible in a conventional case course. Also available on the website was at least one, but usually two or three conceptual articles or book chapters relevant to the week's issue.

\section{F. Presentation}

The presentation itself was conventional for a case course, except that it was all on the web (no paper). The volume of material and its real-time context were unique. The real-time context made possible some unique learning opportunities. For example, the most compelling moment in the course came when a team 
of students who had won a competition for "best analysis of the week" reported on their prize, which was a trip to a trade show with the case company managers. It's hard to describe the feeling of student "ownership" of the case that was present in the classroom.

\section{THE RESEARCH STUDY}

\section{A. Statement of the Problem}

Traditional case method courses are known for creating and sustaining an engaged learning environment. The real-time case project, because it is a dramatic variation on the traditional case method, aspired to achieve even greater student engagement. The following report takes a close look at one class' perceptions of their learning environment with regard to levels of student engagement. The North Central Regional Educational Laboratories describe engaged learning as follows: "highly engaged learners take an active role in meaningful tasks and activities. They assume increasing responsibility for their own learning and demonstrate their understanding. They explore a variety of resources and strive for deep understanding through experiences that directly apply to their lives, promote curiosity and inquiry and stimulate new interests." Engaged learning is a worthy goal for educators because it increases the likelihood that students will both enjoy the learning process and attain intended learning outcomes.

\section{B. Research Question}

Due to the unique features of the real-time case course (the real-time element, the opportunity to influence a real organization, and the reality that other students from other schools are doing the same), do students consider their levels of engagement to be less than, the same, or more than the levels they experience in traditional case method courses?

\section{Method}

The engaged learning framework, used in this report, is drawn from research conducted by the North Central Regional Educational Laboratories (NCREL). NCREL is one of ten regional educational laboratories that provide research-based expertise, resources, assistance and professional development opportunities for teachers, administrators, and policymakers. The indicators of engaged learning referred to in the following study include:

- Amount of time spent on course tasks

- Challenging nature of the assignments

- Multidisciplinary nature of the work

- Authenticity of the assigned tasks

- Amount of collaboration with classmates

- Degree to which the collaboration is valued

- Level of participation

- Excitement and Enthusiasm (energized learning)

For the purposes of this report, two other dimensions were added:

- Level of motivation

- Level of competition 
The real-time case (RTC) class that was the focus of this study, was an elective graduate business course in entrepreneurship at the Isenberg School of Management. The class was profile was as follows:

\begin{tabular}{|l|c|}
\hline Total Students & 9 \\
\hline Business & 8 \\
\hline Education & 1 \\
\hline & \\
\hline Male & 5 \\
\hline Female & 4 \\
\hline
\end{tabular}

This particular class was selected for two reasons. First, all of the students had experienced case learning prior to taking this course, thus making it possible to compare this course to experiences in other case method courses. Second, the focus group could be easily conducted with all of the students in attendance. One limitation of this study is its inability to generalize due to:

- Small size of class

- Students self-selected into this elective course

Data analyzed in this study was collected by 1) administering a short, written survey and 2) conducting a focus group. It was determined that these methods of gathering data would be the most effective means to directly discern student experiences in this course. Students completed a ten-question survey during the last hour of their weekly three-hour class, approximately $2 / 3$ of the way through the semester.

The survey questions asked students to compare their experience with RTC with the experiences they remembered having in traditional case courses. Questions were phrased as follows: Compared to traditional case learning that you have experienced... (the indicator was stated) the real-time case is, in general...: Students responded using a Likert scale from 1(a lot less)-5(a lot more). A score of 3 indicated no difference. A copy of the survey is available from the authors.

Immediately following the completion of the survey, a focus group interview was conducted. For approximately 45 minutes, four primary questions were asked. The questions focused on broad categories anticipating that the discussion, with facilitation, would cover additional topics (see Focus Group Results below).

\section{Survey Results}

Mean scores for the survey are given below. It is interesting to note that on all but one of the engaged learning indicators, the real-time case method scored above the traditional case method. Given the fact that these students studied a real company in real-time, it is not surprising that authenticity of work scored the highest. However, it was unexpected that students' sense of competition was less than that found in traditional case learning. This is particularly surprising given that students from other universities were participating in this same case study, and all of the students submitted weekly analyses to the case company.

The focus group interview, that immediately followed the completion of this survey, provided additional meaning to the survey results. 


\begin{tabular}{|c|c|}
\hline Authenticity of work (real world relevance) & 4.75 \\
\hline Level of excitement and enthusiasm & 4.66 \\
\hline Level of motivation & 4.27 \\
\hline The multidisciplinary nature of the work & 4.22 \\
\hline Degree to which collaboration is valued & 4.10 \\
\hline Challenging nature of the case assignments & 3.77 \\
\hline Level of participation in class discussions & 3.66 \\
\hline Amount of collaboration with classmates & 3.44 \\
\hline Amount of time required to analyze a case assignment & 3.38 \\
\hline Sense of competition & 2.66 \\
\hline
\end{tabular}

\section{E. Focus Group Results}

The nine students in the class were quite willing to participate in the focus group. The high overall enthusiasm about the course was evident by listening to the responses to the first group question. This question was intended to open a broad discussion about the level of excitement and enthusiasm for the course.

\section{Question 1: What has the real-time case course been like for you?}

I like the depth advantage it has.

This is a constant changing issue, no matter what topic we're discussing.

I think that's (new developments and changes) one of the better components of the course.

I feel like maybe I have had some sort of impact on decisions that the company makes.

We can pretend that we have the potential for impact, and the kind of follow-up that we get, the in-depth perception of getting to know a company makes it more emotionally engaging. I care more about it (the company).

You see somebody outside of class and you just start talking about it, wondering what they will do, if things will work out. And that happens much more often, you know, compared to older traditional cases I took.

You're kind of rooting for certain people.

The elements of engaged learning that emerged from this question were:

Authenticity of the assigned tasks: (Tasks that pertain to the real world) Several students commented that they enjoyed the opportunity to impact company decisions. They also felt that there was an advantage to knowing the players (company managers) to help them better understand the company's decisions.

Excitement \& Enthusiasm (energized by learning): (Learners are not dependent on rewards from others, they have a passion for learning) Comments such as-the enthusiasm that extended to conversations outside of class, appreciating the depth advantage and uncertainty inherent in studying one company so thoroughly, caring about the players, rooting for certain people-all reflect a level of energy for learning that is not always apparent in other classes. 
A follow-up question was asked about levels of participation in the class. Two students mentioned that they believed there was an error in the question. They stated that because it was a much smaller class than they were typically used to, a higher level of participation was inevitable.

\section{Question 2: To what extent did this class affect your collaboration with your classmates either during or after class? Also talk about the degree to which you valued different perspectives in this class.}

As seen below, this question provided an interesting discourse on the students' perception of collaboration.

Every week one person has to write a (class paper) and has to put together a unified opinion of the class... So I definitely think there is more collaboration than any other classes where we're actually told not to talk to other people about the cases.

Two students disagreed with the above statement.

I feel much less collaboration than in other classes. It has nothing to do with the nature of the cases, but just how the class is set up.

I think in other classes there is a lot more group work... Everyone brings in their own individual ideas (to class each week) and the class then pulls it together.

The student who initially felt that there was more collaboration in this class later clarified the comments.

I think we collaborate much more during class than other classes where we had cases. There it's almost competing against each other.

A different student agreed that there was more collaboration in this class.

Here we look for solutions. Other classes we try to defend the opinion-which is completely different.

One of the students who had believed that there was less collaboration agreed that this class was more about building consensus. In the statement below the student is indicating that the RTC course is structured in a way that encourages group consensus, which is different that what the student has experienced in other case method classes.

We're trying to come up with a final product that's some kind of best consensus. We're consciously working toward that goal during class time. (In other case classes) I would be trying to get the best consensus in my own head, but that's not how those classes were structured (toward the goal of obtaining group consensus).

The follow-up question addressed the issue of valuing the collaboration and perspectives of classmates. Themes that emerged were the collegial nature of the class, the opportunity to hear new and different perspectives, and a style of teaching that encouraged thorough discussion and in-class collaboration. 
I think it's more collegial. In a traditional case study class you are probably trying to come up with a spin on a certain fact buried in the case that you are going to raise your hand and get credit for.

In a traditional case you quite often have an instructor with a case that he's maybe taught 15 times and you know in the back of your head that this guy has got an idea of what the answers are and you try to meet those. Whereas here, that's gone and we all try to bring in whatever we can. And it feels to me more collaborative, and it feels more genuine.

Prof. Theroux isn't hesitant to bring it up when he has an opinion from his experiences, but he does it in a way that's - not that this is the right answer - but 'this is my kind of addition to the conversation.'

He definitely gives us time though to come up with those ideas... He usually gives us ample time to kind of bat the idea around.

It's not like you are using what you have already learned. Your learning is going on, you are still learning more things than you knew before.

Some of the elements of engaged learning that emerged from this question were:

Level of competition: (This was not one of the NCREL indicators of engaged learning, but was added as an extra research item). This was the lowest survey response question compared to traditional case learning. The comments about collegiality and coming to consensus and finding solutions are the opposite of a competitive learning environment.

Amount of collaboration: (Leaner develops new ideas and understanding in conversations with others). While there was initially a difference of opinion regarding collaboration, the discussion revealed that a different form of collaboration transpired in this particular RTC class. However it is unclear whether this form of collaboration was due to the real-time case or due to the structure of the class and the particular teaching style of the professor.

Degree to which the collaboration is valued: (Class discussion brings in new ideas, the focus is on consensus). The students' discussion revealed they highly valued their collaborative efforts in this class.

This was particularly emphasized in their comments regarding consensus building.

Question 3: In what ways did this course require you to challenge your thinking, stretch your thinking or think at a higher level?

In responding to this question, the MBA students compared their experiences in this RTC class with another course, taught in the first year, that is conducted using the traditional case method. While it was not the intention of this study to compare specific courses or professors students have had, the responses of MBA students to this question were very specific and directed to comparisons with this first year course. 
Another point of interest regarding the challenging nature of the case was that some students felt that the challenge originated from a different source. It was more internally driven-the potential to come up with suggestions for the company was a great motivator. The fact that other schools were participating in this course added to one student's motivation to write strong, well considered, weekly analyses. A few students also believed that having to consider multiple variables added to the complexity of these weekly analyses.

One student commented that realism adds to the complexity of the course due to having to factor in significant environmental variables. The fact that this case was taught in the fall of 2001, and began the week before 9/11, may have made this more apparent than it might have been in another year.

It's definitely been the most challenging course besides marketing. Here (compared to courses besides marketing) there is more of a thought process.

I think that maybe the source of the challenge is making the difference... I mean it's internal...the potential to come up with something that the company can use...is a better motivator to try to apply myself more.

I think it's more challenging because you have to consider many variables... Some of the solutions I might have in my head wouldn't work for that company because all of these things are intertwined, there are just so many different things we know about the company and certain solutions are just not feasible.

Here I really have much better grasp on the industry and I think knowing more about it fine tunes your thinking. It probably gives you the ability to come up with more focused solutions... There are many more variables to think about and it can definitely be more challenging.

This last response seems to get at the heart of the distinction of this real-time, real company case. Compared to traditional cases, several students thought that some solutions that were generated in case discussions may have been completely unrealistic, but there was no way to test them. Also, because the students knew so much more about all of the issues of this company (marketing, finance, operations, etc.) each decision became more complex.

The HBS (Harvard Business School) cases that we analyze already have exhibits tables created for us. Here if we want a table...we have to make it so it makes us think more. It's not already done for us.

(In marketing and this class) the professor doesn't give us the question. We have to dig through the case and find it... I think it makes you think a lot more about what the whole case is about, what the whole company is about, who that issue is going to affect.

The next comment was with regard to how the case material was presented.

I think in regular cases they give you the information that they want you to know. Whereas here we have a nonbiased case writer... If we need more information we can pretty much easily get it. Prof. Theroux is up there (at the company) all the time. 
The discussion became directed at interesting differences between this case class and a marketing class offered to MBA students in their first year.

Marketing was very challenging and you really wanted to be precise in your thinking. You knew that you were going to have to be presenting something that the professor would challenge you on. It was almost like fear driven in some way. Whereas this class, I almost don't even feel like it's so challenging because it's not fear driven, it's fun driven... It's intrinsically challenging...you know Prof. Theroux is not going to give you a hard time if you say something silly, but you know all your classmates are going to build on that idea and go with it. I think in that way it's perhaps equally challenging but it feels really different.

Here it's challenging, but...it's fun challenging. It's not like I'm stressed when I'm in this class out of fear.

I think it goes back to the way...the whole class is structured as a group. (here we're not comparing our answers to others) It's like we're collaborating to get to a group consensus and that takes a lot of pressure off.

Several students commented on the fact that this case has no real conclusion, given that they are not looking at it historically, they are looking at it in real-time.

(In traditional cases) the company actually made a choice and you can see those consequences. Here there is none of that. The company makes a choice but we won't see the consequences for years. There just is no right answer, really.

I think that's why marketing is always compared with this class because it was stressed that there is no right answer. In other case classes, the questions were so leading that there was a right answer... I think this is what business is all about. You don't know what the right answer will be.

I'm starting to feel some frustrations. We come together, bring ideas with what we think they ought to do. I'm a little frustrated that we're not going to know. At times I say to myselfwhatever, move on, because I don't know, I'm not ever going to know...an occasional frustration with the ambiguity.

Such is life and such is the business world... I think this class really hones in on that point that you have to live with ambiguity, because that is what life is, especially the business world.

Some of the elements of engaged learning that emerged from this question were:

Challenging nature of the assignments: (Requires students to stretch their thinking and their social skills) Most of the students felt that this RTC course was more challenging than other case courses, except for marketing. The non-MBA students, also thought that this was more challenging. The survey results on this dimension indicated that this course was only slightly more challenging when compared to traditional case learning that they had experienced, but the focus group provided more of an indication that it was, in fact, considerably more challenging. 
Multidisciplinary nature of the work: (Involves integrating disciplines to solve problems and address issues) A few students commented on the class as being more challenging because they had to consider more variables regarding the company and the industry.

Authenticity of the assigned tasks: (Pertains to the real world) The prevalent feeling seemed to be that there was no 'right answer', and the mirroring of real business ambiguities, made it more authentic and challenging.

Level of competition: (Not one of the NCREL indicators of engaged learning, but was added as an extra research item) Most of the students agreed that because the goal of the group was to come to consensus, there was limited competition when compared to differently structured classes.

Level of motivation: (Not one of the NCREL indicators of engaged learning, but was added as an extra research item) The motivation to perform well was intrinsic and fun-driven according to a few students.

Question 4: What do you take away from this experience? What skills have you developed? Are these skills applicable to your professional life?

Although specific skill development is not a goal of an engaged learning environment, it is a probable outcome when students are working on real-world tasks. Thus this research question sought to identify what specific skills students developed while taking this course. Unfortunately since there were only a few minutes remaining in our time, when this question was posed, there was little opportunity to probe for more specifics.

I think it's really helped me listen to what other people have to say... as opposed to... trying to think of how I'm going to combat (another student's) answer, or think of why mine is so much better... It's not like I have to beat (another student's) answer so that I look good (in front) of the teacher... Here I think it's a much more friendly non-competitive environment where we all look to each other to find an answer.

I think this course has developed my listening skills... In here we synthesize the thoughts after each class, especially when it's your week to write the paper.

The knowledge of the cell industry is really interesting... Somewhere in my professional life I'll have some way to leverage (this).

I like the way you learn about one industry in particular.

I think it's more realistic in terms of being in a job. You're going to have to know all about the industry, all about the competition, all about these factors. I think this course exposes you to what it's really going to be like out there in the real world. (In the real world) you're going to have to listen to people and their ideas instead of trying to fight them and prove them wrong.

I have developed an appreciation... as to how difficult some of these issues are in the real world as compared to having them tidily encapsulated into cases. These are big nasty issues. 
Seeing how difficult it is (selling a product at a trade show) and how concise you have to be... I think it is nice to comprehend the difficulties the company faces even just getting the message out... If you just talk about it, you don't have any experience.

If I ever do start a business I'll definitely come back to the thinking that we did in this class.

It takes a little bit of everything we learned in the first year...kind of ties them all together.

It’s a good capstone course.

Hence, skills developed in listening, collaboration, and consensus building. Additionally, students noted an appreciation for developing their knowledge of the industry, starting a business, and an awareness of the difficulty of dealing with these real world issues.

\section{CONCLUSIONS}

This study sought to investigate whether students in a course using a real-time case study found their learning experiences more engaging than their experiences in traditional case courses. The data, collected via a survey and a focus group discussion, indicate that the real-time case, combined with the structure of the class and the teaching style of the professor, created a learning environment that the students found to be highly engaging. However, due to the limited nature of this study, its results may not be generalized to other RTC courses.

Determining the degree to which the RTC model independently contributed to the engaged learning environment is beyond the scope of this study. However, it is clear that the RTC model played an important role. For example, the periodic submissions of class recommendations to the case company led to collaboration and consensus building among the students. Because collaboration and consensus were emphasized, students noted a decreased sense of competition among themselves compared to courses where the traditional case method is utilized.

Additionally, the students reported a higher sense of authenticity with the real-time case and attributed this to increasing their motivation in this class as well. The fact that students viewed themselves as getting to know the company players relatively well and having the potential to impact a real company, helped create this sense of authenticity. Moreover, the real-time element precluded any final outcome to the case. This is in stark contrast to the traditional case study method where, given its historical nature, an outcome from decisions made is already known. It might be interesting for a future study to investigate the impact of RTC on teaching style and class structure.

Thus, the results of this study support the use of real-time cases to provide highly engaged learning environments that are different than those found in courses using traditional case studies, especially along the dimensions of authenticity, collaboration, challenge, excitement and enthusiasm. Additional differences included consensus building and a reduced sense of competition among the students. Furthermore, the real-time nature of this method has implications for how RTC courses may need to be structured differently than courses utilizing the traditional case study method. Finally, it was apparent that students appreciated the opportunity to participate in a course utilizing the real-time case method. 
It is acknowledged that this study is limited in that it only investigated the experiences of one class utilizing the real-time case. Future articles will report on data from the other classes, including standard course evaluation data from one of the participating universities.

\section{ABOUT THE AUTHORS}

Clare Kilbane (B.A., University of Dayton; M.A. The Ohio State University; Ph.D., University of Virginia) is an assistant professor at the University of Massachusetts Amherst. She is interested in the effect of new technologies on students and instructors in traditional classrooms and online learning environments.

Jim Theroux (B.A., University of Wisconsin; M.B.A., Harvard Business School; EdD, University of Massachusetts) is the Flavin Professor of Entrepreneurship at the Isenberg School of Management at the University of Massachusetts Amherst. He studies new ways of using technology for business education. 